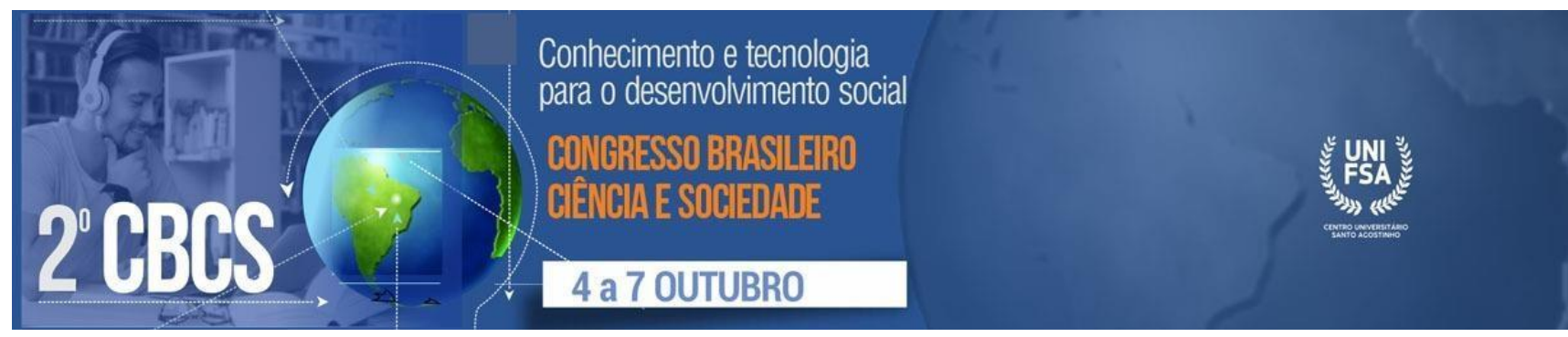

\title{
SERVIÇO SOCIAL NA SAÚDE: DESAFIOS DO TRABALHO DO(A)S ASSISTENTES SOCIAIS NA PANDEMIA DA COVID-19 EM TERESINA-PI ${ }^{1}$
}

\author{
Gisélia Maria da Silva Carvalho, UFPI ${ }^{2}$ \\ Lúcia da Silva Vilarinho, UFPI ${ }^{3}$
}

\begin{abstract}
RESUMO
O presente artigo apresenta parte da discussão realizada no minicurso Serviço Social na saúde e o trabalho interprofissional na pandemia da covid-19, ministrado na IX Jornada Científica de Serviço Social da Universidade Federal do Piauí-UFPI, nos dias 27 e 28 de maio de 2021, com o tema "Serviço Social no contexto da pandemia: desafios para a formação e o trabalho profissional". Com a pandemia, os desafios postos ao trabalho das Assistentes Sociais na área da saúde, trazem à tona velhas e novas problemáticas, cujas soluções impõem a necessidade de repensar as estratégias profissionais mediante a ação coletiva, na superação da barbárie e do avanço do neoliberalismo e conservadorismo.
\end{abstract}

Palavras-chave: Serviço Social. Saúde. Pandemia da covid-19. Neoliberalismo.

\section{INTRODUÇÃO}

Esse artigo, elaborado com base na discussão realizada no minicurso "Serviço Social na saúde e o trabalho interprofissional na pandemia da covid-19", organizado e ministrado na IX Jornada Científica de Serviço Social da Universidade Federal do Piauí-UFPI, nos dias 27 e 28 de maio de 2021, com o tema "Serviço Social no contexto da pandemia: desafios para a formação e o trabalho profissional", em parceira com mais três assistentes sociais da Fundação

\footnotetext{
${ }^{1}$ Trabalho apresentado no 2 Congresso Brasileiro Ciência e Sociedade (CBCS 2021), promovido pelo Centro Universitário Santo Agostinho, de 04 a 07 de outubro de 2021, em Teresina-PI.

${ }^{2}$ Assistente Social da Fundação Municipal de Saúde-FMS, Teresina-PI; Mestranda do Programa de Pós-Graduação em Políticas Públicas da Universidade Federal do Piauí-UFPI.

${ }^{3}$ Professora do Curso de Serviço Social da Universidade Federal do Piauí. Doutora em Desenvolvimento e Meio ambiente pela rede PRODEMA/UFPI; Docente do Programa de Pós-Graduação em Políticas Públicas da Universidade Federal do Piauí-UFPI.
} 
Municipal de Saúde de Teresina, tem como foco a discussão da política de Saúde e o autoritarismo ultraneoliberal na pandemia da covid-19, e os seus reflexos nos processos de trabalho do(a) Assistente Social na referida política. Destaca a atuação profissional na atenção especializada, no hospital municipal Dr. Miguel Couto - Monte Castelo, em Teresina, referência no atendimento de pessoas com covid-19.

\section{METODOLOGIA}

Trata-se de um estudo analítico descritivo, baseado na realidade vivenciada no Serviço Social de um hospital com atendimento exclusivo para pessoas com suspeita ou confirmação de covid-19 no município de Teresina, cujas demandas para o Serviço Social batiam à porta de maneira indevida, cabendo cotidianamente aos profissionais os seus rebatimentos.

O trabalho está organizado em três partes. Na primeira parte são discutidos os rebatimentos do ultraneoliberalismo de direita na condução da pandemia de covid-19. $\mathrm{Na}$ segunda, descreve-se os reflexos desses rebatimentos no processo de trabalho do(a) Assistente Social, analisando as perspectivas e os desafios postos aos profissionais. Na última, tecem-se as considerações finais.

\section{POLÍTICA DE SAÚDE NO BRASIL NO CONTEXTO DA PANDEMIA DA COVID-19}

Desde dezembro de 2019, o Brasil, assim como outros países do globo recebia a notícia, pela grande mídia, de um alerta sobre uma nova cepa de coronavírus, em Wuhan, na China, que pouco tempo depois seria responsável por uma das mais graves crises social e humanitária do planeta, a pandemia da COVID-19. Os coronavírus são considerados, uma ampla e variada família de vírus que podem causar uma infinidade de sintomas, desde o resfriado comum ou leve a doenças mais graves, como é o caso das síndromes respiratórias agudas graves, causadas pelo SARS-CoV. A situação é confirmada com a declaração da Organização Mundial de Saúde - OMS, em janeiro de 2020 de que as mazelas do novo coronavírus constituem o que se denomina de Emergência de Saúde Pública - ESPII, considerado o nível mais alto de alerta da OMS. Para se ter uma dimensão da pandemia, é a sexta vez na história que uma Emergência de Saúde Pública de Importância Internacional é declarada. Em março do mesmo ano, pela rápida disseminação da doença em vários países do mundo, a Covid-19 é considerada pela Organização Mundial de Saúde como uma pandemia. 
Conforme Santos (2021, p.231), “a pandemia do coronavírus é um acontecimento histórico de proporções só comparáveis à gripe espanhola, que atingiu o mundo no final da Primeira Guerra Mundial, à depressão de 1929 e à Segunda Guerra Mundial”. Para o autor, as lições que se podem tirar desse acontecimento, são um tanto desafiadoras, uma vez que se pode ter um ciclo intermitente de pandemia a desafiar a vida de cada povo, independente da região ou localização geográfica.

A referência ao autor é feita a partir do pensamento de que a pandemia encontrou o Brasil imerso em um cenário de crise do Estado, que também escancarou as mazelas já existentes no país e denunciou o agravamento das expressões da questão social (BRAVO; MATOS; FREIRE, 2020).

Não obstante a isso, verifica-se a opção do Estado Brasileiro, frente à pandemia, pelo capital, em detrimento das pessoas, no caso específico, a classe que mais tem sido afetada pela pandemia, que é a classe trabalhadora, conforme aponta Santos (2020):

A explícita opção das classes dominantes pela lógica da economia capitalista e sua sanha em busca de acumulação e lucratividade em detrimento da proteção à saúde e à vida, evidenciou o quanto, no jogo da luta de classes, a classe trabalhadora, em toda sua heterogeneidade e diversidade, está sendo radicalmente atacada e perde ainda mais: direitos, acesso ao trabalho, condições de saúde e, a depender da vontade política do Estado brasileiro, notadamente em seu comando federal, perde a própria vida (SANTOS, 2020, p. 9-10).

Notadamente, que essa faceta do neoliberalismo, não é recente, mas se acentuou com a pandemia e tem gerado efeitos drásticos no campo das políticas sociais, em especial a de saúde. Verifica-se que ao longo dos anos, a própria história da Saúde Pública no Brasil tem sido marcada por sucessivas reorganizações administrativas, edições de muitas normas além de disputas de interesses políticos e sociais.

Conforme Bravo; Lima; Correia (2020), desde a década de 1990, o Estado brasileiro tem capitaneado esforços para minimizar suas ações, em atendimento às demandas da classe trabalhadora, e maximizar sua atenção para as demandas do capital. Segundo as autoras, o fundo público, por exemplo tem sido cada vez mais utilizado nas políticas sociais implementadas pelo setor privado, favorecendo o aparecimento de novos modelos de gestão, cuja finalidade é o desmonte das políticas de estado.

Bravo et al (2009), já sinalizava há anos que o que se está em jogo é a disputa perene de dois projetos de saúde, de um lado o projeto de saúde articulado ao mercado, ou o que a autora denomina de privatista, pautado na racionalização da oferta, e de outro o público, ou 
que se pode chamar de projeto da reforma sanitária. Ambos propõem requisições diferentes para a prática do Serviço Social.

Entretanto, verifica-se que o projeto privatista tem ganhado força com a crescente mercantilização da saúde pública, como forma de desburocratizar e modernizar o Estado, no intuito do enfrentamento da crise do capital, o que tem favorecido cada vez mais os interesses do grande capital empresarial e financeiro, especialmente na saúde (BRAVO; LIMA; CORREIA, 2020).

O momento atual, de pandemia e de flerte da nova direita com os ideários ultraneoliberais é marcado pelo exacerbamento de preconceitos contra as minorais, de descrédito da ciência e das instituições públicas e o aprofundamento do neoconservadorismo. O Ultraneoliberalismo seria um novo ciclo do liberalismo ultra-acirrado, uma nova etapa do projeto neoliberal, onde as práticas políticas e sociais vêm sendo reorientadas por um conservadorismo de direita, também exacerbado denominado por vários estudiosos de ultraneoconservadorismo (BORGES E MATOS, 2020).

Ressalva-se, que além da disputa de projetos de saúde, há também a disputa de projetos de classe, evidenciada pela "defesa do lucro acima da vida" versus a "defesa da vida acima do lucro". E essa disputa já estava em curso no Brasil. A chegada da pandemia no país, só revela o oportunismo do capital e intensifica, cada vez mais, o agravamento das expressões da questão social.

O Brasil, na contramão das orientações dos organismos de saúde, não soube enfrentar a pandemia da forma que se esperava, uma vez que não houve por parte do governo federal planejamento das ações de enfrentamento da covid-19. Nesse contexto, fica claro o descompasso dos Estados e municípios, frente à falta de direção única nesse enfretamento. Além disso, o constante duelo entre os três níveis de gestão, aliado a uma conjuntura de desgoverno, negacionismo e ultraconservadorismo impôs ao país índices alarmantes de contaminação e morte da população mais vulnerável.

Diante de tal realidade, cabe-nos a pergunta: como os/as assistentes sociais enfrentam o confronto desses projetos em evidência nas instituições do trabalho profissional? É o que tentaremos responder na seção a seguir.

\section{OS REBATIMENTOS DO ULTRANEOLIBERALISMO NO PROCESSO DE TRABALHO DO(A) ASSISTENTE SOCIAL NA PANDEMIA DA COVID-19}


Várias são as legislações que embasam o trabalho do(a)s assistentes sociais na política de saúde. São resoluções que subsidiam a prática profissional e o seu conhecimento confronta diretamente as requisições conservadoras e indevidas aos profissionais. Conforme Borges e Matos (2020, p.83):

Requisições conservadoras fazem parte historicamente do trabalho de assistentes sociais. Afinal, uma profissão que se funda no trato das expressões da questão social, recebe requisições diversas, sobretudo do empregador, para a individualização dos "problemas" apresentados pelos usuários, dificultando a compreensão dos problemas como expressão da desigualdade inerente à lógica e dinâmica capitalista. Responder requisições conservadoras, concordando com as mesmas, faz parte de uma determinada concepção ético-política de profissão e ao mesmo tempo, é objeto de negação de uma conceção crítica, que buscou superar esse conformismo que fez parte, explicitamente, da profissão, por largo tempo.

Diante de uma realidade de morte em detrimento da vida, o(a) assistente social tem como imperativo ético-político a negação daquilo que vai de encontro aos seus preceitos e normativas éticas da profissão e em favor da defesa da vida. Com a pandemia, o grande capital também faz inúmeras requisições, travestidas de solidariedade, em momentos de calamidade. As ações antes executadas, tais como as ligadas ao atendimento direto aos usuários, supervisão direta aos estagiários, as visitas às enfermarias, por exemplo, foram suspensas, reestruturando-se os atendimentos aliados às medidas de segurança e distanciamento, ressurgindo, por outro lado, tanto pela equipe quanto pela gestão, a solicitação de velhas requisições.

O Hospital Dr. Miguel Couto - Monte Castelo, em Teresina-PI, foi o primeiro hospital municipal a receber exclusivamente pacientes com suspeita ou confirmação de covid-19. Em março de 2020 iniciou suas atividades com 5 leitos de UTI, e 2 de estabilização, além dos leitos de clínica médica, perfazendo um total de 50 leitos.

A estrutura hospitalar foi modificada, para se adequar às exigências impostas pela letalidade do vírus. Profissionais médicos, de enfermagem e fisioterapia já faziam parte do quadro funcional, só que agora em uma outra realidade: de comunicação truncada pelos equipamentos de proteção individual, medo da contaminação, desespero dos familiares, despreparo da equipe em determinados momentos e falta de apoio psicológico para profissionais e pacientes.

A realidade da práxis profissional do(a)s assistentes sociais com a pandemia também se tornara outra. Sem desconhecer a responsabilidade diante de uma situação pandêmica, as 
profissionais de Serviço Social da instituição buscaram apoio na família, como suporte para enfrentar o vírus, até então desconhecido.

O espaço sócio-ocupacional do Serviço Social foi requisitado, tornando-se uma sala de "paramentação", devido sua localização estratégica, assim como as demais salas próximas que foram também sendo adaptadas para essa nova realidade. O Serviço Social e suas profissionais então foram inseridos na "área limpa", fazendo parte do espaço administrativo, no qual a direção geral do hospital se encontrava. A rotina hospitalar já não tinha a mesma cor tão pouco o mesmo movimento.

A maioria dos profissionais adequou suas vestimentas e calçados, sendo as categorias de atendimento direto, como médicos, técnicos de enfermagem, enfermeiros, fisioterapeutas priorizados quanto à disponibilização de EPIs. Uma das lutas travadas com a gestão recaiu sobre a disponibilização também para o Serviço Social de luvas, protetor facial, máscaras, aventais impermeáveis, etc., já que as profissionais também se expunham diariamente no contato com o(a)s familiares contactantes, e possivelmente também infectado(a)s.

Foi realizada a articulação com as demais assistentes sociais da rede estadual de saúde para poder entender o funcionamento desses hospitais, do trabalho profissional e assim, traçar o planejamento de protocolos e fluxos de atendimento específicos ao contexto da pandemia. Além disso, após a definição dos fluxos, realizava-se o contato com as profissionais dos hospitais da rede municipal para a socialização de informações concernentes ao contexto sociofamiliar e de saúde dos usuários, bem como o repasse dos contatos telefônicos para as equipes, no intuito da comunicação do boletim médico.

Coube às assistentes sociais, o acolhimento, a escuta da família, por telefone ou presencialmente, as orientações sobre as normas e rotinas, a não presença de acompanhante e não realização de visita presencial, a organização dos documentos de alta e a interlocução com a família, nesses casos. É pertinente evidenciar que, em certos momentos, tendo como critério o distanciamento, chegou-se a realizar atendimentos presenciais na calçada e se formavam pequenas filas de familiares em busca de notícias de seus parentes hospitalizados.

Parte desses familiares puderam sanar a falta de informação com o atendimento remoto, por meio das "visitas virtuais", sempre realizado com o apoio da equipe de nutrição e com a avaliação da equipe médica ou de enfermagem. $O$ próprio contato com a equipe era de forma remota, por meio de skype. Como não era permitido o uso de celular, toda a comunicação era feita por meio da tecnologia. As orientações em caso de óbito (acesso ao benefício eventual, no caso da urna funerária), encaminhamentos para a rede eram e continuam, nesse contexto pandemico a ser presenciais. 
Notadamente, e por outro lado, além das demandas institucionais e das famílias, as demais categorias profissionais também requisitavam e ainda requisitam das assistentes sociais a adesão à ações historicamente demandadas, porém não executadas, pelo entendimento de que não seriam atribuições do Serviço Social. Tais requisições tem se constituído nas demandas que nenhum outro profissional "quer fazer": tais como receber, identificar e guardar pertences, comunicar óbito e entregar declaração de óbito aos familiares, dentre outras.

No entanto, é importante salientar que, o não atendimento das requisições indevidas em questão, se consubstanciam no conhecimento do código de ética, do projeto éticopolítico, das legislações que amparam o fazer profissional, das normativas emitidas pelo conjunto CFESS-CRESS e na luta, dentro da instituição, pela consolidação de uma práxis comprometida e crítica da realidade.

Com o aumento dos casos e internações, foi observada a necessidade de mais profissionais de Serviço Social, pois muitas famílias estavam deixando de ser atendidas, às vezes o(a) paciente ia a óbito e não era realizado o acolhimento social, devido principalmente ao número excessivo de demandas. Foram sendo incorporadas duas novas assistentes sociais, para o final de semana, visto que só tinham duas profissionais diaristas, nos dois turnos, de segunda a sexta-feira.

Num balanço da atuação do Serviço Social na saúde, no contexto pandêmico, mesmo com todas essas problemáticas enfrentadas no cotidiano do fazer profissional, observa-se a necessidade do trabalho do(a)s assistentes sociais, no sentido de garantir às famílias de usuários internados o acesso à informação, a universalidade de atendimento, igualdade e integralidade das ações em saúde.

Apesar de um momento pleno de desafios, a conjuntura atual suscita o direcionamento da categoria profissional para o repensar de estratégias no cotidiano do fazer profissional e a superação da barbárie, em tempos de neoliberalismo e (neo)conservadorismo que tanto tem impactado a vida de milhares de pessoas, especialmente no contexto pandêmico, até então vivenciado.

\section{CONCLUSÕES}

Os rebatimentos do ultraneoliberalismo no processo de trabalho do(a) assistente social na pandemia da covid-19 tem se feito presente em todos os espaços sociocupacionais do Serviço Social. Entretanto, mesmo reconhecendo e vislumbrando a presença do projeto de 
saúde privatista no âmbito municipal, observa-se a despeito, que a luta dos profissionais que acreditam nos ideais da reforma sanitária também tem tensionado a disputa entre os projetos público e privado. E cada vez mais, tem possibilitado a resistência. Se o(a)s assistentes sociais são linha de frente política, os desafios e os enfretamentos só serão possíveis se forem coletivos, social e politicamente também. A privatização da saúde e o sucateamento das políticas sociais públicas, mediante ajustes da política ultraneoliberal são realidades pungentes, que precisam ser desveladas de forma conjunta e em união com a classe trabalhadora. Sejamos parte dessa realidade, sejamos luta, sejamos classe trabalhadora.

\section{REFERÊNCIAS}

BRAVO, M.I.S; MATOS, M. C. de; FREIRE, S. de M. Apresentação. In.: BRAVO, M.I.S; MATOS, M.C.; FREIRE, S.M.(Org.). Políticas sociais e ultraneoliberalismo. Uberlândia: Navegando Publicações, 2020, p.19-24.

BRAVO, M.I.S; LIMA, J.B de; CORREIA, M.V.C. Privatização e mercantilização da saúde e crise no Rio de Janeiro: o desmonte realizado pelas organizações sociais. In.: BRAVO, M.I.S; MATOS, M.C.; FREIRE, S.M.(Org.). Políticas sociais e ultraneoliberalismo. Uberlândia: Navegando Publicações, 2020, p. 125-146.

BRAVO, M.I.S. MATOS, M.C. Reforma Sanitária e projeto ético-político do Serviço Social: elementos para o debate. In.: BRAVO, M.I.S. et al. (orgs.) Saúde e serviço social - 4 ed. - São Paulo: Cortez; Rio de Janeiro: UERJ, 2009, p.25-47.

OPAS - Organização Pan-Americana da saúde. Histórico da pandemia de COVID-19. Disponível em: https://www.paho.org/pt/covid19/historico-da-pandemia-covid-19. Acesso em 31.08.2021

SANTOS, B.S. O futuro começa agora: da pandemia à utopia. 1. ed. - São Paulo: Boitempo, 2021.

SANTOS, S. M. M. Prefácio. In: JOAZEIRO, E. M. G.; GOMES, V. B. (orgs). Serviço social: formação, pesquisa e trabalho profissional em diferentes contextos. Teresina: EDUFPI, 2020. E-book 